\title{
The Gravity of Unwanted Thoughts: Asymmetric Priming Effects in Thought Suppression
}

\section{Citation}

Najmi, Sadia, and Daniel M. Wegner. 2008. The gravity of unwanted thoughts: Asymmetric priming effects in thought suppression. Consciousness and Cognition 17: 114-124.

\section{Published Version}

http://dx.doi.org/10.1016/j.concog.2007.01.006

\section{Permanent link}

http://nrs.harvard.edu/urn-3:HUL.InstRepos:2380002

\section{Terms of Use}

This article was downloaded from Harvard University's DASH repository, and is made available under the terms and conditions applicable to Open Access Policy Articles, as set forth at http:// nrs.harvard.edu/urn-3:HUL.InstRepos:dash.current.terms-of-use\#OAP

\section{Share Your Story}

The Harvard community has made this article openly available.

Please share how this access benefits you. Submit a story.

Accessibility 


\title{
The gravity of unwanted thoughts: Asymmetric priming effects in thought suppression
}

\author{
Sadia Najmi *, Daniel M. Wegner \\ Department of Psychology, Harvard University, 33 Kirkland Street, WJH 1244, Cambridge, MA 02138, USA
}

Received 4 September 2006

Available online 6 March 2007

\begin{abstract}
An unwanted thought appears to be cued easily by reminders in the environment but often the thought itself seems to cue nothing more than the desire to eliminate it from consciousness. This unusual asymmetry in the way unwanted thoughts are linked to other thoughts was the focus of the present research. Participants who were asked to suppress a thought or to concentrate on it completed a task assessing the influence of priming on reaction time (RT) for word/ non-word judgments. Results revealed that suppression under cognitive load produced asymmetric priming: Priming with the associate of a suppressed word speeded RT for the suppressed word, but priming with a suppressed word did not speed RT for associated words. These findings suggest that thought suppression induces an unusual form of cognitive accessibility in which movement of activation toward the suppressed thought from associates is facilitated but movement of activation away from the suppressed thought to associates is undermined.
\end{abstract}

(C) 2007 Elsevier Inc. All rights reserved.

Keywords: Thought suppression; Hyperaccessibility; Priming

All too often, we find our consciousness drawn to a particular unwanted idea by most everything that comes to mind. But the idea itself seems to remind us of nothing much at all-except perhaps the fact that we would like not to think it. Unwanted thoughts have unusual gravity - an attractiveness that makes it easy for the mind to move toward them but difficult for it to move away. This power of suppression of unwanted thoughts reveals itself in an asymmetric pattern of reminding: Although anything related to an unwanted thought seems to remind us of that thought, the thought itself does not seem to remind us of other related things. This potential asymmetry of associative priming in suppression was the focus of this experiment.

To grasp this asymmetry, consider the predicament of an obsessive-compulsive disorder patient: The patient is convinced that encountering the number 7 will compel him to hurt someone. He tries not to think about the number, yet it seems that the idea of doing math homework turns his attention to it, as does a countdown in a game with friends, or even a glance at the clock. Cues in the environment automatically turn him toward the number 7, as do his own random thoughts when they drift too near the number. Once his focus is

\footnotetext{
* Corresponding author. Fax: +1 6174953728.

E-mail address: najmi@fas.harvard.edu (S. Najmi).
} 
captured by the thought of 7 , however, few cues in his surroundings can distract him from it. He does not seem to think of a 7-11 store, seventh heaven, the seven deadly sins, or any of a number of other related ideas that a person without his concern might have had come to mind on thinking of the number. The unwanted thought seems to give rise to an asymmetry of association, in which many associates act as reminders of the unwanted thought whereas the thought itself is something of a dead end, failing as a reminder of any of its usual associates.

Research has demonstrated two manifestations of the gravity of suppressed thoughts- the ease of return to suppressed thoughts, and the difficulty of escape from suppressed thoughts. An initial observation of ease of return by Wegner, Schneider, Carter, and White (1987) found that after a period of thought suppression, people instructed to discontinue suppression of the thought and instead to begin thinking about it reported more returns of the thought than occurred without prior suppression. This is particularly likely to happen under conditions of mental load. The ease of return illustrated by this "rebound effect" has since been observed repeatedly (see reviews by Abramowitz, Tolin, \& Street, 2001; Rassin, 2005; Wegner, 1989; Wenzlaff \& Wegner, 2000), including in studies with clinical samples. For example, Shipherd and Beck (1999) showed the inability to suppress rape-related thoughts in PTSD patients, Harvey and Bryant (1998) showed the same effect for accident-related thoughts in survivors of motor vehicle accidents with acute stress disorder, and Conway, Howell, and Giannopoulos (1991) showed impaired suppression of negative thoughts in dysphoric individuals. Common to these studies with clinical and non-clinical populations is the finding that the unwanted thought is faster to return to consciousness when it is being actively suppressed.

The difficulty of escape from suppressed thoughts has been found in studies examining the phenomenon of hyperaccessibility in interference effects. Wegner and Erber (1992) found that people suppressing a thought under cognitive load showed interference with the task of color-naming in a modified Stroop (1935) paradigm-more so than the interference found when people were concentrating on the thought under load. In essence, people could not switch attention to escape from the unwanted thought, and this difficulty became more pronounced with the imposition of cognitive load or distraction. This effect, too, has been observed repeatedly (e.g., Arndt, Greenberg, Solomon, Pyszczynski, \& Simon, 1997; Newman, Duff, \& Baumeister, 1997; Page, Locke, \& Trio, 2005).

To account for such effects, Wegner (1994) proposed an ironic process theory of mental control. The theory suggests that thought suppression is accomplished by two cognitive search processes - an intentional operating process that consciously and effortfully searches for mental contents that are not the unwanted thought, and an ironic monitoring process that unconsciously and less effortfully searches for the unwanted thought. The processes work together to yield suppression, in that the relatively uninterruptible ironic process remains alert to the unwanted thought and prompts the operating process to be re-initiated if the unwanted thought returns to awareness. By maintaining such vigilance, however, the ironic monitoring process is likely to usher unwanted thoughts into awareness whenever competing cognitive demands undermine the effectiveness of the conscious operating process. These processes might explain both the ease of return to suppressed thoughts and the difficulty of escape from those thoughts.

The studies mentioned above support the notion of ease of return to, and of difficulty of escape from, suppressed thoughts. However, to date there have been no studies that have investigated the potential asymmetry of suppressed thoughts - the idea that thinking of things associated with the unwanted thought promptly results in a return to the unwanted thought, but that once back on the thought, it is difficult to disengage even to closely associated thoughts. Ironic process theory suggests that the suppression of a thought should influence the symmetry of associative pathways surrounding the thought. To appreciate this influence, it is worth noting that most theories of the association of thoughts - such as Collins and Loftus's (1975) spreading activation model - assume that the direction of associative links between thoughts is stable. The flow of thought is represented as a network of concepts or nodes, and the activation of a concept leads to activation of associated concepts that are nearby in the network. Although particular pairs of thoughts may exhibit asymmetrical associative links (e.g., nose leads to job more strongly than job leads to nose) these pathways of activation are understood as given by learned patterns of word association, not by transitory variations in mental control (e.g., Thompson-Schill, Kurtz, \& Gabrieli, 1998).

Ironic process theory suggests that thought suppression under mental load should create asymmetric priming. If during suppression the operating process diverts attention away from the unwanted thought, it should 
do so by strengthening the activation of pathways away from the thought in the associative network. Under mental load, this function of the operating process would be inhibited and pathways away from the unwanted thought should weaken. At the same time, the ironic monitor maintains vigilance for the unwanted thought by scanning the network for the unwanted thought, activating associated nodes in the network that lead toward the unwanted thought. The ironic process thus should strengthen paths from associates toward the suppressed thought.

We tested asymmetric priming in a facilitation paradigm based on Meyer and Schvaneveldt's (1971) finding that responses to a target word are faster when it is preceded by a semantically related word. Although the priming effect in these studies has been referred to as semantic, Shelton and Martin (1992) found robust priming effects only for associated word pairs, as determined by word association norms (e.g., bread-butter), and not for word pairs that are semantically related but not associated in terms of temporal contiguity in speech or text (e.g., bread-cake). Hence, in our study, we used word association norms (Palermo \& Jenkins, 1964) to obtain prime/target pairs. Our prediction was that during suppression under cognitive load, facilitation should be greater when the prime is an associate of the suppressed word and the target is the suppressed word than when the prime is the suppressed word and the target is an associate.

\section{Method}

\subsection{Overview}

Participants were instructed either to think about (concentration condition) or not think about (suppression condition) one of two words (house or mountain). These mental control focus words used by Wegner and Erber (1992) were highly familiar and had mutually exclusive sets of associated words. During the concentration or suppression task, participants first verbalized their stream of consciousness for 5 min. Next, while continuing to concentrate or suppress, they performed an associative priming lexical decision task by indicating whether each of a series of letter strings on a computer screen was a valid word in English or a non-word. The words included the mental control focus word, associates of that word, and unrelated words. Cognitive load was manipulated across blocks of trials with instructions simultaneously to rehearse either a 9digit (high load) or 2-digit (low load) number (cf. Gilbert \& Osborne, 1989).

\subsection{Participants}

Participants (72 women, 26 men) were undergraduates in psychology courses at Harvard University who received course credit for participation and others who responded to advertisements and were paid for participation. Their mean age was 20.6 years $(S D=5.8)$.

\subsection{Procedure}

Participants were randomly assigned to a suppression or concentration condition and their consent was obtained to participate in a study of how mental tasks affect the way people make word judgments.

\subsubsection{Stream of consciousness task}

Depending on condition, participants were instructed to think or to not think about an item (house or mountain) and to verbalize their thoughts alone in a room to a tape recorder for $5 \mathrm{~min}$. Mental control instructions were those used by Wegner et al. (1987).

\subsubsection{Associative priming lexical decision task}

Before the task, participants were asked to continue to suppress or concentrate on the item while alone in the room for $1 \mathrm{~min}$ (but without verbalizing).

For the suppression condition, the participant turned to a computer and the experimenter instructed: 
Now you're going to continue to try not to think of a house (or mountain) while you perform another task at the same time. We will do some practice trials but first I will go over the instructions with you. You will see a series of letter strings on the screen. During each trial the first letter string will be presented for a very short duration and the second one will be presented for a longer duration. You are to read both the first and the second letter string but respond only to the second letter string. If the second letter string is a word in English, press the left key. If it is a non-word, press the right key. Try not to make mistakes, but try to be fast. Your reactions will be timed. A + will appear on the screen before each letter string appears to show you where to look. Please respond as quickly as you can.

Participants in the concentration condition received the same instruction, except that they were reminded to continue to try to think of a house (or mountain) during the computer task.

For participants in both conditions, instructions for the cognitive load task were then given:

In addition to studying people's ability to identify words, we are also interested in finding out how they do when they perform another task at the same time. Your job will be to respond to the letter string and at the same time remember a number that will appear before each block of experimental trials, that is, a group of trials. You will be asked to say the number aloud at the end of each block. It is very important that you say the number back exactly as it appears on the screen. If you fail to remember the number, the group of trials will have to be disqualified from this study.

There were 16 practice trials followed by 180 test trials. Test trials were presented in 6 blocks with a different 9-digit or 2-digit number for each block. Half the trials in each block were performed under high load and half under low load. Verbal recall of the number for each block of trials was recorded on audiotape.

Stimuli were presented and RTs recorded using Empirisoft DirectRT v2004 software (Jarvis, 2004). The task was based on the method of McRae and Boisvert (1998, Expt. 1). Each trial consisted of a fixation point "+" for $250 \mathrm{~ms}$, followed by the prime for $200 \mathrm{~ms}$, a mask ("\&\&\&\&\&\&\&") for $50 \mathrm{~ms}$, then the target, which remained on screen until the participant responded. The inter-stimulus interval was $1500 \mathrm{~ms}$. Stimulus words were the same for all participants with the same mental control focus word for suppression or concentration, although half the participants were presented the words in reverse order. One hundred and eight filler trials were added to allow 50\% "yes" trials for the lexical decision of the target word so that the proportion of unrelated targets that were non-words was .5. To eliminate the relatedness proportion effect (increased priming with greater proportions of trials in which the prime and target are related; Neely, Keefe, \& Ross, 1989), the proportion of valid English target words preceded by a related prime was set at .3.

Associated words were the 4 most frequent associates of the mental control focus word according to the norms of Palermo and Jenkins (1964). For mental control focus word house, associates included home, door, brick, and roof. For focus word mountain, the associates were hill, high, top, and climb. To avoid "backward priming effects" (Koriat, 1981), prime/target pairs were chosen from the norms such that an association exists in both directions: prime/target and target/prime. Backward priming is facilitation for prime/target pairs in which there exists an association from the target to the prime in the absence of an association from the prime to the target and may be a function of semantic matching/integration rather than spreading activation (Chwilla, Hagoort, \& Brown, 1998). Results of a paired $t$-test conducted on the word-associationstrength data (Wilson, 1988) for words chosen for the current study confirmed that there was no significant difference in association strength between associate-to-focus and focus-to-associate prime/target pairs, $t(7)=.58, p=.6$.

The prime/target pairs for both critical and filler trials contained a random ordering of ten prime/target pair-types (see Table 1). Additionally, constraints were placed on randomization such that the same word (prime or target) was never presented in two consecutive trials, and that the prime and target were distinct words in all trials.

Following the computer task, participants completed questions on their mental control efforts and were debriefed and dismissed. 
Table 1

Types of prime/target pairs presented in associative priming lexical decision task

\begin{tabular}{lll}
\hline Prime & Target & Prime/target example \\
\hline Focus & Associate of Focus & house/roof \\
Focus & Unrelated to Focus & house/priest \\
Associate of Focus & Focus & roof/house \\
Associate of Focus & Associate of Focus & roof/door \\
Associate of Focus & Unrelated to Focus & roof/king \\
Unrelated to Focus & Unrelated to Focus and related to prime & lamp/light \\
Unrelated to Focus & Unrelated to Focus and unrelated to prime & moon/bread \\
Focus & Non-word & house/marpis \\
Associate of Focus & Non-word & roof/marpis \\
Unrelated to Focus & Non-word & moon/marpis \\
\hline
\end{tabular}

Focus: Mental Control Focus Word.

\section{Results}

\subsection{Data exclusion}

Tapes for all sessions were reviewed to verify participant adherence to the number-recall instruction at the end of each block of trials. These showed that all but 7 participants recalled the cognitive load numbers. Data for the 7 participants who did not recall all cognitive load numbers correctly were excluded from analyses. Other participants who were tested but whose data were not analyzed included 6 with high mean RTs (>850 ms), 2 with over 3 errors in the lexical decision task, and 1 who did not complete the experiment. Thus, data for a total of 86 participants were analyzed.

\subsection{Mental control manipulation checks}

To explore effects of the mental control instruction, occurrences of the mental control focus word (house or mountain) were examined in the stream of consciousness reports. As is predicted when suppression is not disabled by competing cognitive demands (Wegner, 1994), participants mentioned the mental control focus words less often under suppression $(M=5.89)$ than concentration $(M=18.43), F(1,85)=24.84, p<.001$. Post-task responses to the items "How hard did you try not to think about house (or mountain)?" and "How hard did you try to think about house (or mountain)?" were examined in a $2 \times 2$ analysis of variance (ANOVA). The interaction of mental control instruction and question type was significant, $F(1,83)=34.29, p<.001$, such that suppressing participants reported more effort not thinking about the target $(M=3.14)$ than effort thinking about it $(M=2.09), t(43)=2.76, p<.01$, and concentrating participants reported more effort thinking about the target $(M=4.93)$ than effort not thinking about it $(M=2.61), t(40)=-5.34, p<.001$.

\subsection{Associative priming lexical decision task}

In all latency analyses, trials on which an error occurred were excluded. Trials with latencies greater than 3 $S D$ s above the mean were also excluded.

Mean RTs were examined in three ANOVAs - one on the priming of mental control focus words by their associates (associate-to-focus priming analysis), another on the priming of associates by mental control focus words (focus-to-associate priming analysis), and a third examining simultaneously the priming for associate to focus and focus to associate (priming asymmetry analysis).

\subsubsection{Associate-to-focus priming}

One side of the hypothesized asymmetric effect of thought suppression is that during suppression under high load associates of the suppressed thought will readily prime that thought.

To explore priming of mental control focus words by their associates, trials in which the prime was an associate of the mental control focus word and the target was an unrelated word, another associated word, or the 
focus word were examined in an ANOVA with instruction (concentration, suppression) and focus-word (house, mountain) as between-participants variables and cognitive load (low, high) and target type (mental control focus word, associate, unrelated) as repeated measures. The highest order significant effect was the interaction of instruction, load, and target type, $F(2,164)=3.77, p<.03, \eta^{2}=.04$ (see Fig. 1). Focus-word did not appear in any significant effects, so the analysis proceeded with the decomposition of this interaction.

Simple simple main effects of target type were computed for each combination of instruction and load. For low load, standard priming effects arose for concentration. A significant simple simple effect of target type appeared for concentration under low load, $F(2,168)=4.65, p<.01$, and simple simple contrasts showed that priming with an associate speeded $\mathrm{RT}$ to the focus word $(M=508 \mathrm{~ms})$ compared to unrelated words ( $M=557 \mathrm{~ms}), F(1,84)=6.87, p<.01$, and speeded RT to other associates ( $M=517 \mathrm{~ms})$ compared to unrelated words $(M=557 \mathrm{~ms}), F(1,84)=7.30, p<.01$. When primed by an associate, RT for focus word $(M=508 \mathrm{~ms})$ and $\mathrm{RT}$ for other associates $(M=517 \mathrm{~ms})$ were not significantly different.

Marginally significant priming differences between target types were observed under low load for suppression, $F(2,168)=2.83, p=.06$, and simple simple contrasts revealed that suppression under low load reduced associate priming of the focus word $(M=574 \mathrm{~ms})$ compared to priming of associates $(M=534 \mathrm{~ms})$, $F(1,84)=5.35, p<.02$. Neither of these values was significantly different from the mean for associate priming of unrelated words $(M=552 \mathrm{~ms})$. This suggests a modest propensity for effective suppression of the focus word under low load, in that participants were slowed in thinking of the suppressed word by mention of the word's associates relative to their speed of thinking of one associate by mention of another.

A different picture emerged under high load, however, where suppression produced significant priming by the associate (see Fig. 1). A significant simple simple effect of target type appeared under high load in the suppression condition, $F(2,168)=4.63, p<.01$, and simple simple contrasts showed that priming with an associate in this condition speeded RT to the focus word $(M=549 \mathrm{~ms})$ compared to unrelated words $(M=592 \mathrm{~ms}), F(1,84)=5.36, p<.02$, and also speeded RT to other associates $(M=540 \mathrm{~ms})$ compared to unrelated words $(M=592 \mathrm{~ms}), F(1,86)=7.00, p=.01$ The influence of priming by an associate was not significant under high load for concentration, however, as the simple simple effect of target type in this condition was not reliable, $F(2,168)=.94, p>.39$. The influence of concentration on priming by the associate thus was attenuated by load, whereas the influence of suppression was magnified by load.

In sum, this analysis indicated that standard associative priming effects surfaced for priming by associates of the mental control focus word only under the predicted combinations of load and mental control instruc-

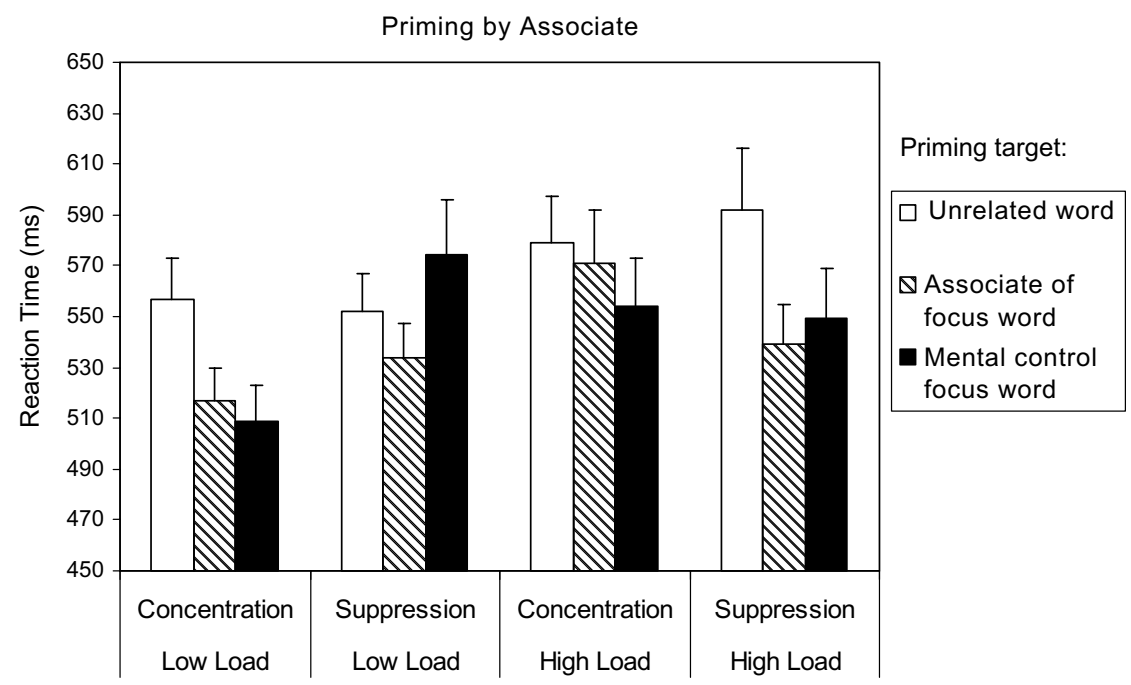

Fig. 1. Mean RTs for the associate-to-focus analysis. Lexical decision RT for priming by associates of a mental control focus word with the target an unrelated word, another associate, or the focus word as a function of instruction (concentration or suppression) and cognitive load (low or high). 
tion. Associates of the mental control focus word primed the mental control focus word (and other associates) during concentration under low load, and during suppression under high load. In a sense, then, priming from associates to the mental control focus word seems to carry on during suppression under load much as it does in the less complicated circumstance of concentration under low load. Associates prime the focus of suppression under load as strongly as they might if the person were merely thinking of the focus word without load. This, then, represents one part of the expected asymmetric effect of thought suppression: During suppression under load, associates of the suppressed thought readily prime that thought.

\subsubsection{Focus-to-associate priming}

The other side of the hypothesized asymmetric effect of thought suppression is that associative priming from target to associate will not occur during suppression, especially when under high load.

This analysis examined the other part of asymmetric priming effects of suppression. Trials in which the prime was the mental control focus word and the priming target was either an associated word or an unrelated word were examined in an ANOVA with instruction (concentration, suppression) and focus-word (house, mountain) as between-participants variables and cognitive load (low, high) and target type (associate of mental control focus, unrelated) as repeated measures (see Fig. 2). Although main effects and interactions were not significant, contrasts were conducted to test expectations in the four load by instruction conditions. In each condition, priming effects from target to associate were compared with priming from target to unrelated word. These simple simple effect tests revealed significant priming for concentration in the low load condition, $F(1,84)=4.54, p<.04$, with reduced $\mathrm{RT}$ for associates $(M=540 \mathrm{~ms})$ compared to unrelated words $(M=578 \mathrm{~ms})$. This facilitation effect was eliminated for suppression under low load, as $\mathrm{RT}$ for associates $(M=561 \mathrm{~ms})$ resembled that for unrelated words $(M=576 \mathrm{~ms}), F(1,84)=2.64, p>.1$. Significant priming was found for concentration under high load, $F(1,84)=4.91, p<.03$, with reduced RT for associates $(M=543 \mathrm{~ms})$ compared to unrelated words $(M=574 \mathrm{~ms})$. These effects were not paralleled, however, by any priming effect in suppression under high load, $F<1$, as there was no significant difference in mean RT for associates $(M=584 \mathrm{~ms})$ and for unrelated words $(M=576 \mathrm{~ms})$. So, although the absence of an overall significant interaction here suggests that these comparisons be viewed with circumspection, the pattern reveals that the associative priming from target to associate that appears during concentration does not surface in suppression, and is clearly absent in suppression under high load.

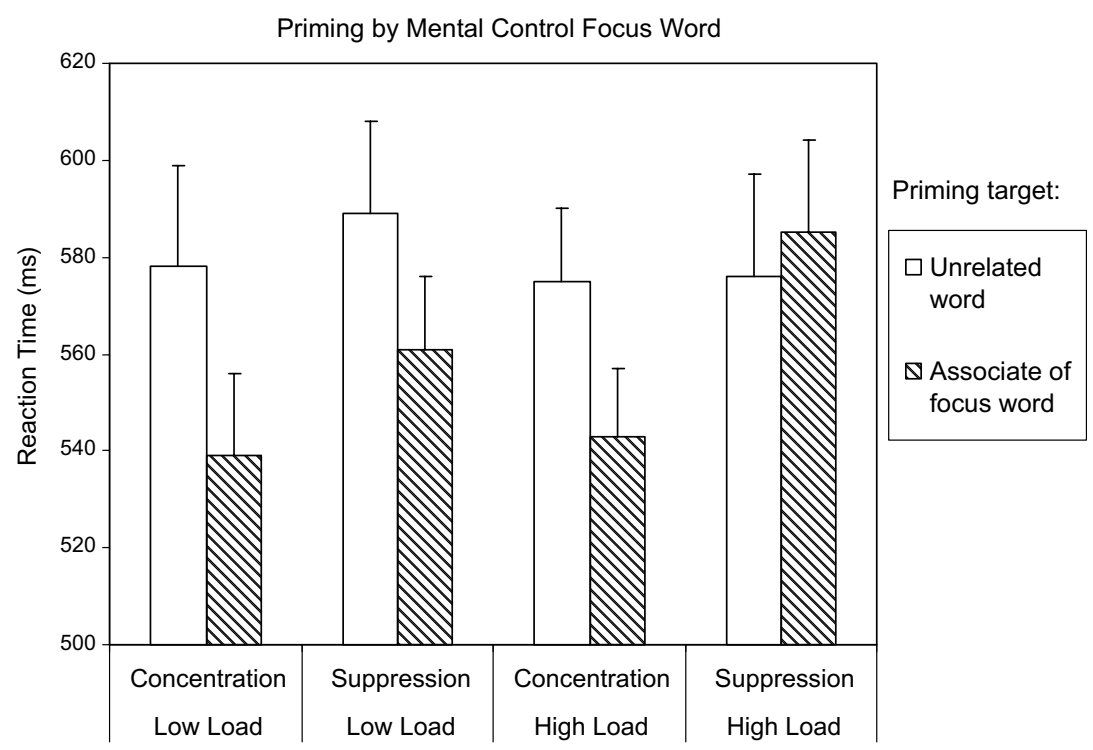

Fig. 2. Mean RTs for the focus-to-associate analysis. Lexical decision RT for priming by a mental control focus word with the target an unrelated word or an associate as a function of instruction (concentration or suppression) and cognitive load (low or high). 


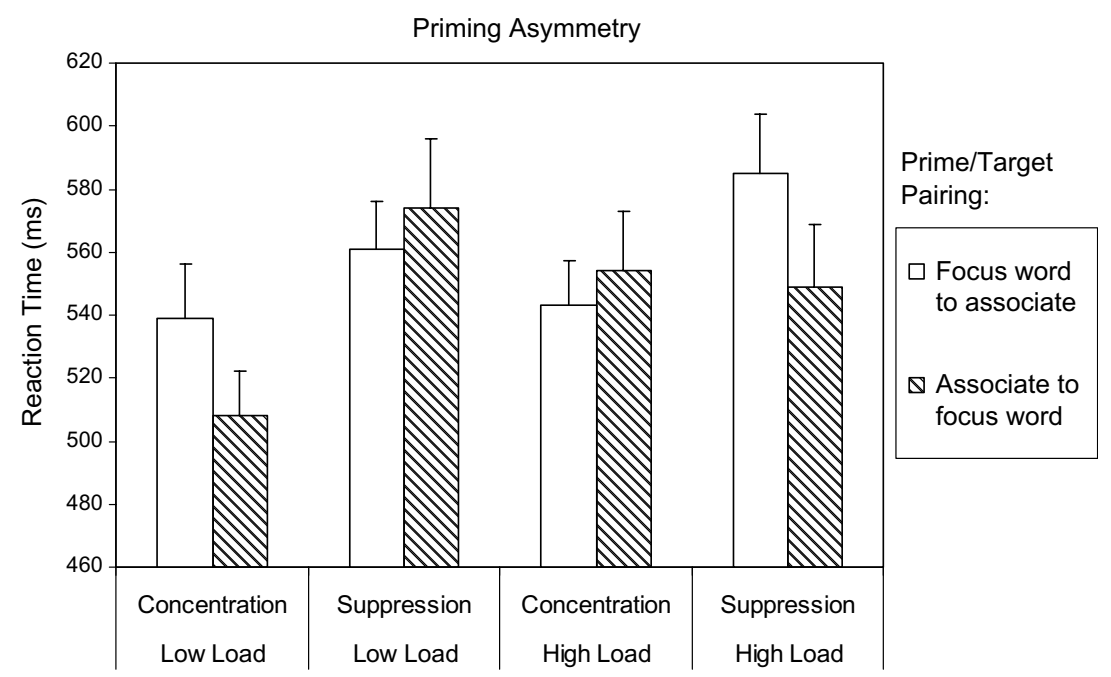

Fig. 3. Mean RTs for the priming asymmetry analysis. Lexical decision RT for an associate primed by a mental control focus word (focus word to associate) or for the focus word primed by its associate (associate to focus word) as a function of instruction (concentration or suppression) and cognitive load (low or high).

\subsubsection{Priming asymmetry analysis}

To examine the asymmetry directly, a further analysis compared priming effects in two directions - from the mental control focus word to its associates, and from the associates to the mental control focus word. This involved comparison of prime/target pairs in which: (a) the prime was the mental control focus word and the target was an associate of the focus word, and (b) the prime was an associate of the mental control focus word and the target was the focus word. This ANOVA explored the RT effects of instruction (concentration, suppression) and focus-word (house, mountain) as between-participants variables and cognitive load (low, high) and pair type (prime $=$ mental control focus and target $=$ associate vs. prime $=$ associate and target $=$ mental control focus) as repeated measures.

This analysis revealed a significant interaction of instruction, pair-type, and load, $F(1,82)=8.73, p<.004$, $\eta^{2}=.10$ (see Fig. 3). There was no higher-order interaction with focus-word, so lower-order effects were not examined further. To examine the 3-way effect, simple simple main effects of pair type were computed for each combination of load and instruction. Only two were significant: During suppression under high load, priming from focus word to associate was marginally significantly slower $(M=585 \mathrm{~ms})$ than priming from associate to focus word $(M=549 \mathrm{~ms}), F(1,43)=3.66, p<.06$; and during concentration under low load, priming from focus word to associate was significantly slower $(M=539 \mathrm{~ms})$ than priming from associate to focus word ( $M=508 \mathrm{~ms}), F(1,41)=4.73, p<.04$. Thus, in concentration under low load and in suppression under high load, priming from associate to focus word was faster than priming from focus word to associate. As reported above, in the case of concentration under low load, priming from focus word to associate was nevertheless significant, whereas in suppression under high load, it was not. Taken together, these results indicate directly the asymmetry of priming produced when people try not to think of something under cognitive load, and the absence of such effects in the other conditions suggests that priming asymmetry is uniquely produced by suppression under load.

\section{Discussion}

In the associative priming lexical decision task, participants who were trying not to think of a word under the mental load imposed by rehearsing a 9-digit number showed an asymmetric pattern of priming between the word and its associates. In lexical decisions, their judgments of the suppressed word were faster when primed by the word's associates. However, when primed by the suppressed word itself, participants did not show facilitation for associates. This can be understood in terms of the gravity of suppression - the extraordinary pull of 
unwanted thoughts and the difficulty of getting away from them. In the concentration condition under low cognitive load, however, priming was symmetric: There was increased facilitation for associates of the focus word when primed by the word itself, and there was increased facilitation for the focus word when primed by its associates.

Network models have indeed been used to explain information processing biases. For instance, Bower's (1981) associative network approach proposes that there exist nodes for mood/affect that are connected to nodes for concepts in the semantic network. Thus, when certain concept nodes are activated, activation spreads to the connected affect node. The research presented here does not focus on affect, but instead on the dynamic property of the strength of activation in the semantic networks. In particular, it underscores the influence of conscious cognitive strategies - in this case, thought suppression - on the strength of activation between interconnected nodes.

The asymmetry of priming for suppression under cognitive load reveals effects predicted by ironic process theory (Wegner, 1994). In suppression under load, the suppressed thought does not prime its associates even while it is primed by its associates. The unintentional ironic process initiated by suppression is not undermined by load and so leads toward the unwanted thought, whereas the intentional operating process also initiated by suppression is undermined by the load and so does not prompt the unwanted thought to prime its associates. Like the gravitational field surrounding a body of great mass, suppression under load makes a thought easy to return to and difficult to escape. Thus, suppression of an unwanted thought may ironically turn it into an idée fixe, incessantly returning the thought to itself and precluding other thoughts from entering into awareness. Early theories of psychopathology focused on the idée fixe-a thought that intrudes repeatedly upon consciousness and becomes difficult to control - as the hallmark of mental disorder (Janet, 1894; Ribot, 1881). Although theories of psychopathology have grown more sophisticated than this, there remains evidence that unwanted intrusive thoughts surface as symptoms across a surprising range of disorders, from anxiety and obsessive-compulsive disorders to depression and beyond (Clark, 2005).

The asymmetry in the way unwanted thoughts are linked to other thoughts is apparent in several forms of psychopathology - such as loss or threat-related thoughts in depression and anxiety. Indicators such as performance on the emotional Stroop task reveal that, whereas nonclinical participants show increased interference for current concern related stimuli, clinical patients in general show increased interference for both personal relevance and the negativity of the material (see review by Williams, Mathews, \& MacLeod, 1996). Thus, the more unwanted a thought is, the higher the predicted interference. Some explanatory models have focused on the strengthening of pathways in the semantic network (Beck, Emery, \& Greenberg, 1985; Bower, 1981). The strength of pathways determines the speed of activation in the pathway, which in turn determines the speed of response in reaction time tasks. The focus of the current study was the transitory increase in strength of certain pathways (from associates to the unwanted thought) and transitory decrease in strength of other pathways (from the unwanted thought to its associates) during active attempts at suppression. Thus, the study highlights the transitory gravity of suppression - the extraordinary pull of unwanted thoughts and the difficulty of getting away from them while actively suppressing. These findings raise questions for future research on individual differences in mental control; future research should investigate this phenomenon more directly with clinical samples, particularly in disorders of perseverative thinking.

It is often the case that obsessive thoughts have no obvious beginnings. For example, in the case of patients with obsessional thoughts, it is nearly impossible to identify when the unwanted thought of contamination or asymmetry first gained acute emotional significance. According to Wegner's theory of synthetic obsessions (1989), one contributing factor in the etiology of pathological obsession may very well be the tendency to suppress them. Indeed, active resistance is a defining feature of obsessions. Moreover, although the persistence of unwanted intrusive thoughts characterizes clinically significant obsessions, several studies have established that the experience of unwanted intrusive thoughts is a normative phenomenon (Purdon \& Clarke, 1993; Salvokskis \& Harrison, 1984). These studies show that what differentiates "clinical" intrusive thoughts from "normal" ones is that they are more frequent, distressing, perceived to be less controllable, and more strongly resisted using misguided mental control strategies such as thought suppression (Janeck \& Calamari, 1999; Rachman \& de Silva, 1978). The current study elucidates a potential cognitive mechanism by which suppression may facilitate the progression from normal unwanted thoughts to obsessions. 


\section{Acknowledgments}

This research was supported by a fellowship from The Sackler Scholar Program in Psychobiology to Sadia Najmi and by NIMH Grant 49127 to Daniel M. Wegner.

\section{References}

Abramowitz, J. S., Tolin, D. F., \& Street, G. P. (2001). Paradoxical effects of thought suppression: a meta-analysis of controlled studies. Clinical Psychology Review, 21, 683-703.

Arndt, J., Greenberg, J., Solomon, S., Pyszczynski, T., \& Simon, L. (1997). Suppression, accessibility of death-related thoughts, and cultural worldview defense: exploring the psychodynamics of terror management. Journal of Personality and Social Psychology, 73, $5-18$.

Beck, A. T., Emery, G., \& Greenberg, R. L. (1985). Anxiety disorders and phobias: a cognitive perspective. New York: Basic Books.

Bower, G. H. (1981). Mood and memory. American Psychologist, 36, 129-148.

Chwilla, D. J., Hagoort, P., \& Brown, C. M. (1998). The mechanism underlying backward priming in a lexical decision task: spreading activation versus semantic matching. The Quarterly Journal of Experimental Psychology, 51, 531-560.

Clark, D. A. (2005). Intrusive thoughts in clinical disorders: Theory, research, and treatment. New York: Guilford Press.

Collins, A. M., \& Loftus, E. F. (1975). A spreading-activation theory of semantic processing. Psychological Review, 82, 407-428.

Conway, M., Howell, A., \& Giannopoulos, C. (1991). Dysphoria and thought suppression. Cognitive Therapy and Research, 15, $153-166$.

Gilbert, D. T., \& Osborne, R. E. (1989). Thinking backward: some curable and incurable consequences of cognitive busyness. Journal of Personality and Social Psychology, 47, 940-949.

Harvey, A. G., \& Bryant, R. A. (1998). The effect of attempted thought suppression in acute stress disorder. Behavior Research and Therapy, 36, 583-590.

Janeck, A. S., \& Calamari, J. E. (1999). Thought suppression in obsessive-compulsive disorder. Cognitive Therapy and Research, 23, 497-509.

Janet, P. (1894). Histoire d'une idee fixe. Revue Philosophique, 37, 121-163.

Jarvis, B. (2004). DirectRT (Version v2004) [Computer software]. New York, NY: Empirisoft Corporation.

Koriat, A. (1981). Semantic facilitation in lexical decision as a function of prime-target association. Memory \& Cognition, 9, 587-598.

McRae, K., \& Boisvert, S. (1998). Automatic semantic similarity priming. Journal of Experimental Psychology: Learning, Memory, and Cognition, 24, 558-572.

Meyer, D. E., \& Schvaneveldt, R. W. (1971). Facilitation in recognizing pairs of words: evidence of a dependence between retrieval operations. Journal of Experimental Psychology, 90, 227-234.

Neely, J. H., Keefe, D. E., \& Ross, K. L. (1989). Semantic priming in the lexical decision task: roles of prospective prime-generated expectancies and retrospective semantic matching. Journal of Experimental Psychology: Learning, Memory, and Cognition, 15, 1003-1019.

Newman, L. F., Duff, K., \& Baumeister, R. F. (1997). A new look at defensive projection: thought suppression, accessibility, and biased person perception. Journal of Personality and Social Psychology, 5, 980-1001.

Page, A. C., Locke, V., \& Trio, M. (2005). An online measure of thought suppression. Journal of Personality and Social Psychology, 88, 421-431.

Palermo, D. S., \& Jenkins, J. J. (1964). Word association norms. Minneapolis: University of Minnesota Press.

Purdon, C. L., \& Clarke, D. A. (1993). Obsessive intrusive thoughts in nonclinical subjects. Part I. Content and relation with depressive, anxious and obsessional symptoms. Behaviour Research and Therapy, 31, 713-720.

Rachman, S. J., \& de Silva, P. (1978). Abnormal and normal obsessions. Research and Therapy, 16, $233-248$.

Rassin, E. (2005). Thought suppression. New York: Elsevier.

Ribot, T. (1881). Les Maladies de la mémoire. Paris: Baillière.

Salvokskis, P. M., \& Harrison, J. (1984). Abnormal and normal obsessions - a replication. Research and Therapy, 23, 571-584.

Shelton, J. R., \& Martin, R. C. (1992). How semantic is automatic semantic priming? Journal of Experimental Psychology: Learning, Memory, and Cognition, 18, 1191-1210.

Shipherd, J. C., \& Beck, J. G. (1999). The effects of suppressing trauma-related thoughts on women with rape.

Stroop, J. R. (1935). Studies of interference in serial verbal reactions. Journal of Experimental Psychology, 18, 643-662.

Thompson-Schill, S. L., Kurtz, K. J., \& Gabrieli, J. D. E. (1998). Effects of semantic and associative relatedness on automatic priming. Journal of Memory and Language, 38, 440-458.

Wegner, D. M. (1989). White bears and other unwanted thoughts: Suppression, obsession, and the psychology of mental control. New York: Viking/Penguin.

Wegner, D. M. (1994). Ironic processes of mental control. Psychological Review, 101, 34-52.

Wegner, D. M., \& Erber, R. E. (1992). The hyperaccessibility of suppressed thoughts. Journal of Personality and Social Psychology, 63, 903-912.

Wegner, D. M., Schneider, D. J., Carter, S., III., \& White, L. (1987). Paradoxical effects of thought suppression. Journal of Personality and Social Psychology, 53, 5-13. 
Wenzlaff, R. M., \& Wegner, D. M. (2000). Thought suppression. In S. T. Fiske (Ed.). Annual review of psychology (Vol. 5, pp. 59-91). Palo Alto, CA: Annual Reviews.

Williams, M. G., Mathews, A., \& MacLeod, C. (1996). The emotional Stroop task and psychopathology. Psychological Bulletin, 120, 3-24. Wilson, M. D. (1988). The MRC psycholinguistic database: machine readable dictionary, Version 2. Behavioural Research Methods, Instruments and Computers, 20, 6-11. 